\title{
Context Shift and Indexical Variables in Sign Languages
}

\author{
Josep Quer \\ ICREA \& Universitat de Barcelona
}

\section{Introduction}

The linguistic resources displayed by sign languages (SLs) in order to reproduce someone else's utterances or thoughts have remained absent from the semantic research on reported discourse till very recently. This paper aims at contributing some fresh SL data to the discussion about the proper characterization of indexical interpretation in reported discourse/thought contexts.

I will defend a unified treatment of quotational and non-quotational use of role shift in SLs, in line with Zucchi (2004) and other previous research. A covert Point of View Operator will be held responsible for the morphological and semantic properties of role shift constructions. One partial conclusion will be that the crosslinguistic validity of the "Shift-Together Constraint" by Anand \& Nevins (2004) might not be instantiated in the SLs examined.

The new data discussed comes mainly from Catalan Sign Language (LSC), the SL used by the Deaf Community in Catalonia. ${ }^{1}$ However, I also undertake limited crosslinguistic comparisons with published American Sign Language (ASL), Lingua Italiana dei Segni (LIS) and Danish Sign Language (DSL) data.

\section{The Properties of Role Shift in SLs}

The grammatical phenomenon known as role shift (RS) (also known as role taking, reference shift or in some instances constructed dialogue, as in Metzger 1995 ) in SLs is often viewed as the equivalent of a direct discourse report or quotation in the visual-gestural modality. It is the genuine means these languages have in order to convey the utterances or thoughts ascribed to a discourse agent, and sometimes to reproduce or rather reconstruct the dialogue between two or more subjects. It mostly appears in the context of narratives. For general characterizations and analyses of the phenomenon, see Engberg-Pedersen (1995), Lee et al. (1997), Poulin (1994), Poulin \& Miller (1995), Lillo-Martin (1995) and Zucchi (2004), among others.

From a formal point of view, RS is typically flagged by a number of nonmanual markings that may include the following ones:

- slight body shift towards the locus in signing space where the author of the reported utterance has been previously located;

- break in eye gaze contact with the actual addressee; gaze directed towards the purported addressee of the reported context;

- change in head position; 
- facial expression (linguistic and affective) associated with the author of the reported utterance.

These nonmanual markings are simultaneously coarticulated with the manual material that is interpreted as the reported proposition.

At the manual level, the main characteristic of RS is that the reference of $1^{\text {st }}$ and $2^{\text {nd }}$ person pronouns and the corresponding verb agreement with subject and object is shifted with respect to the actual context of utterance. Typically, a $1^{\text {st }}$ person pronoun occurring in a RS fragment does not refer to the actual signer but to the signer of the reported context, as we can observe in the LSC example in (1): ${ }^{2}$ the pronominal sign IX-1 ' $\mathrm{I}^{3}$ does not refer to the author of this example, but to the referent of JOAN, the individual to whom the thought is ascribed.

\section{$\mathrm{t}$}

IXa MADRID JOAN ${ }_{i}$ THINK IX- $1_{i}$ STUDY FINISH HERE MADRID

'When he has in Madrid, Joan thought he would finish his studies there in Madrid.'

Unlike in English, for instance, the default interpretation of personal pronouns in the scope of RS is not determined by the utterance context but rather by the context of reported conversation. This is not a particular fact of RS in LSC, but it seems to be recurrent in the other SLs where the RS phenomenon has been attested, as in (2) from ASL.

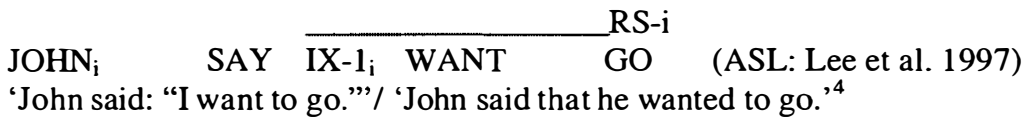

Lee et al. (1997) treat examples of this sort as instances of reported direct speech or direct quotation realized as two juxtaposed clauses. Although such cases do exist, I will show that RS is also attested in constructions where reported direct speech cannot be at play. This has been documented for several sign languages, and for ASL as well (cf. Lillo-Martin 1995, who provides empirical arguments for the embedded status of the reported clause).

In SLs, this strategy with RS constitutes a much more genuine mechanism of reporting someone else's utterance or thought than regular indirect discourse. However, the latter is an existing alternative, as we can see in the exemple in (3). It should be compared with the parallel case with RS in (4). Putting the nonmanual markings of RS aside, the main difference resides in the use of pronominals: the $1^{\text {st }}$ person pronoun in (4) does not get interpreted in the actual context of utterance, but in the derived context.

ANNA $_{i}$ 3-SAY-1 IX-3 FED-UP LOSE+++

'Anna told me that she was fed up with losing so often.' 
As we will see more extensively below, treating RS fragments as direct speech is not always straightforward. On the one hand, LSC has explicit markers of direct quotes such as VOICE, SAY1 SENTENCE, AUTHOR IX-\#, etc. An instantiation of this can be found in (5).

ANNA $_{i}$ EXPLAIN SAYI SENTENCE IX-1 $1_{i}$ BROTHER MAN 3-IGNORE-1 "Anna told me: 'My brother ignores me.",

On the other hand, what appears to be a direct quotation at face value cannot be classified as such due to the interpretation of the indexicals appearing in it. An instance of RS used in a non-direct quotation can be found in (6) from LSC. The crucial fact is that the reported thought could not be a quotation with the intended meaning of the indexical HERE: uttered in Barcelona, HERE refers to Barcelona and not to the reported context.

IXa MADRID MOMENT JOAN $_{\mathrm{i}}$ THINK IX-1 $_{\mathrm{i}}$ STUDY FINISH HERE
'When he was in Madrid, Joan thought he would finish his study in
Barcelona.'

However, as recently discussed in Zucchi (2004) for LIS, RS is not exclusively restricted to quotational environments, and it can also appear outside the scope of an attitude predicate, as in (7): the main clause is not an attitude report in the usual sense, as it is not introduced by a reportive predicate such as 'say' or 'think', but it has the same surface properties as a direct quotation. In this example RS implies that the subject of the agreeing verb DONATE is coreferential with GIANNI. A comparable case in LSC can be found under (8): the RS stretch has to be attributed to the author of the e-mail referred to in the first part of the utterance and the second person pronoun is linked to the actual $1^{\text {st }}$ person that reports having received the e-mail.

RS-i

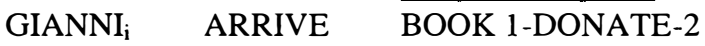

'When Gianni arrives, he will give you the book as a present.'

(LIS: Zucchi 2004)

$\overline{\text { JOAN }}_{\mathrm{i}}$ MAIL ELECTRONIC 3-SEND-1 1 IX-2 ALL GUILT IX-2

'In an e-mail Joan sent to me, he was like 'It's all your fault.',

Some other examples instantiate the possibility for RS to occur independently (non-introduced RS), as in (9) from ASL. As in the previous case, no overt 
predicate introduces the report and only the attitude holder MOM is made explicit.

$$
\begin{aligned}
& \text { MOM }_{\mathrm{i}} \overbrace{\text { IX-1 }} \text { BUSY-i } \\
& \text { 'Mom's like, I'm busy!' }
\end{aligned}
$$

Despite their direct discourse flavor at face value, these instances of nonquotational RS roughly display the same properties with respect to locative and temporal indexicals such as HERE or YEAR-THIS. Although more work is needed on this second group of data, they seem to be crucial for the overall account of context shifting in SLs.

The main conclusion of this brief characterisation of RS in LSs is that irrespective of whether RS is introduced or not by an attitude predicate, the interpretation of the indexical elements occurring in its domain can differ from the one we would expect in direct quotation. In the next section we will try to put these facts into the perspective of indexical interpretation in language in general.

\section{Indexicals that Shift?}

The received view on indexical expressions is that expressions such as $1^{\text {st }}$ and $2^{\text {nd }}$ person pronouns, temporal and locative deictics are directly referential, following the basic approch of Kaplan (1989). This characterization has been summarized by Schlenker in the Fixity Thesis (10).

\section{(10) Fixity Thesis (a corollary of Direct Reference)}

The semantic value of an indexical is fixed solely by the context of the actual speech act, and cannot be affected by any logical operators.

(Schlenker 2003: 29)

Although operators are in principle conceivable that could shift the context of evaluation of an indexical, Kaplan excludes this possibility and calls them 'monsters'. At face value, this view seems to account quite accurately for indexical interpretation in a language like English. However, Schlenker (2003) argues that such monsters do exist and are instantiated in certain languages by attitude predicates. An example of such a shifted indexical would be represented in the following example in Amharic, where the $1^{\text {st }}$ person in the scope of 'say' does not refer to the actual utterer but to John, the reported utterer. 
'John ${ }_{i}$ says that he $_{i}$ is a hero.'

(Lit.: 'John ${ }_{i}$ says that $I_{i}$ am a hero.')

From a crosslinguistic point of view, this is not an isolated case. Languages like Havyaka Kannada (Dravidian), for example, use the same set of pronouns for denoting actual and reported speech act participants. As a consequence, the reference of the embedded $1^{\text {st }}$ person pronoun can be anchored to the reported context of utterance (12i) or to the matrix context (12ii):

$$
\begin{array}{lllllr}
\text { en-na ello:ru-de } & \text { hogaluttavu } & \text { he: l̦i } & \text { ra:ju } & \text { enna-tre } & \text { he:liddã } \\
\text { me.ACC all.EMPH } & \text { praise } & \text { that } & \text { Raju } & \text { me-with } & \text { tell.PERF }
\end{array}
$$

(i) Raju $u_{1}$ has told $\mathrm{me}_{2}$ : "Everybody praises $\mathrm{me}_{1}$."

(ii) Raju has told $m_{2}$ that everybody praises $m_{2}$. (Bhat 2004: 58)

What this example shows is that the semantic value of the same linguistic expression, the $1^{\text {st }}$ person pronoun, is not unambiguosly determined by the actual context of utterance.

Recent work (Anand \& Nevins 2004, Schlenker 2003, Speas 1999) has extensively shown that the Kaplanian analysis of indexicals in the scope of attitude reports is challenged empirically by languages like Amharic, Navajo, Slave or Zazaki, where first person pronouns embedded under a verb of saying, for instance, can corefer with the matrix clause subject (the attitude holder or reported agent), and not necessarily with the actual utterer, as happens in English.

In view of this sort of facts, the definition of indexical expression should arguably be made more precise. According to Schlenker (2003), "an expression qualifies as indexical if its semantic value is determined by some feature of the context of utterance" (Schlenker 2003: 31). For instance, Amharic 'I' in (11) above qualifies as a strict indexical, as it must refer to the speaker of some context, although not necessarily the context of the actual speech act. It differs in that respect from logophoric pronouns, which are only grammatical in embedded contexts.

Schlenker implements his proposal in an extensional semantics, where attitude verbs are quantifiers over contexts of thought or speech and may bind free context variables. The simplified representation of this view can be found under (13) for example (11): $c_{i}$ stands for the context of the reported speech act, and $c^{*}$ for the context of the actual utterance.

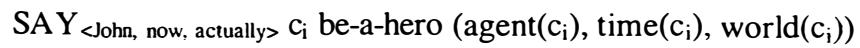

Crosslinguistic variation in the shifting possibilities of indexicals is made dependent on whether the denotations of particular indexicals have free context 
variables or not. In the case under examination, Amharic 'I' would be lexically underspecified for its context variable (14b), as opposed to its English counterpart (14a):

$$
\begin{aligned}
& \text { a. English 'I': }[[I]]=\operatorname{agent}\left(c^{*}\right) \\
& \text { b. } \quad \text { Amharic ' } I \text { ': }[[I]]=\operatorname{agent}(c), c \text { an underspecified context variable }
\end{aligned}
$$

It is further argued by Schlenker that, unlike $1^{\text {st }}$ and $2^{\text {nd }}$ person pronouns, temporal adverbials in English such as "two days ago" shift optionally, as in example (15): only the shifted reading of the temporal expression would yield a felicitous result (15b), while the temporal expression "the day before yesterday" which is indexical to the actual contexts results in infelicity (15a). According to him, this constitutes an argument in favour of treating attitude verbs as quantifiers over contexts rather than as context-shifting modal operators that overwrite all the contextual variables (for the opposite view, though, see Anand \& Nevins 2004, who treat this expression as anaphoric). ${ }^{5}$

(15) John has told me repeatedly over the years: 'I was sick two days ago.'

a. \# John has told me repeatedly over the years that he was sick the day before yesterday.

b. John has told me repeatedly over the years that he was sick two days ago.

On the other hand, under this account logophoric pronouns would be indexicals that can never be dependent on the actual context of utterance, as represented in (16).

$$
\text { Logophoric pronoun: + indexical, }-c^{*}
$$

Mupun (Chadic) (Frajzyngier 1993) instatiates the case of $1^{\text {st }}$ and $2^{\text {nd }}$ person logophoric pronouns as characterized by Schlenker. They are always anchored in the derived context (17b)-(18b), as opposed to the non-logophoric ones (17a)(18a), which refer to the actual discourse participants.

$$
\begin{array}{lll}
\text { a. } & \text { wu sat no n-nas } & \text { wur } \\
\text { 3MSg say that beat.1Sg } & 3 \mathrm{MSg} \\
\text { 'He said that I beat him.' } &
\end{array}
$$

b. wu sat nə di nas an

$3 \mathrm{MSg}$ say that LoglMSg beat $1 \mathrm{Sg}$

' $\mathrm{He}_{1}$ said that he, beat me.'

$\begin{array}{llllll}\text { (18) a. } & \text { n-sat } & \text { n-wur } & \text { no } & \text { wur } & \text { ji } \\ & \text { 1Sg-say } & \text { to-3Sg } & \text { that } & 3 S g & \text { come }\end{array}$ 'I told him that he $_{2}$ should come.' 


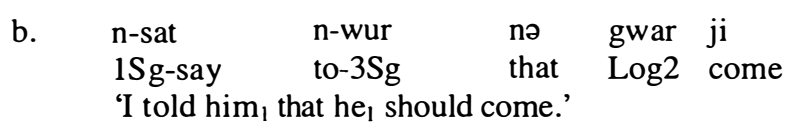

These are the essential features of the framework I am going to assume for the analysis of indexical behaviour in RS in SLs. However, nothing crucial hinges on this particular choice, and probably other approaches that can accommodate the phenomenon of indexical shift and the basic crosslinguistic facts related to it could be adopted.

\section{SL Indexicals in Role Shift}

\subsection{Shifted Second Person Reference}

The published data on RS in different SLs indicates that pronominal reference in reportive contexts behave much as Amharic $1^{\text {st }}$ person pronoun, that is, it is not indexical to the actual utterer, but to the individual to whom the reported attitude is ascribed. Nevertheless, $2^{\text {nd }}$ person reference unsurprisingly shows shifty behaviour as well. In the LSC examples under (19) and (20) this fact is illustrated through verbal agreement: $2^{\text {nd }}$ person on the unbound agreement marker in (19) and on the agreeing lexical verb in (20). ${ }^{6}$

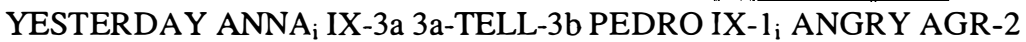
'Yesterday Anna told Pedro that she was angry at him.'

(20) YESTERDAY ANNA $A_{i}$ IX-3a 3a-TELL-1 $\overline{\text { IX-1 } 1_{i} 1 \text {-HELP-2 }}$

'Yesterday Anna told me that she would help me.'

The occurrence in these examples (19) and (20) of $2^{\text {nd }}$ person morphology linked to parameters of the embedded context and not to the actual context of utterance already makes clear that shifted reference of pronouns in RS is not limited to $1^{\text {st }}$ person, as Zucchi's (2004) seems to imply for LIS.

\subsection{Non-shifted Interpretation of Indexicals in RS}

Despite the general tendency for indexical pronouns to shift reference within RS, non-shifted (or back-shifted) interpretations of $1^{\text {st }} / 2^{\text {nd }}$ pronouns in the scope of RS have been also reported for SLs. One such example is (21), taken from EngbergPedersen (1995): in a RS stretch of discourse reporting her mother's signing, the utterer uses $1^{\text {st }}$ person pronouns (regular and possessive pronouns) to refer to herself, where a $2^{\text {nd }}$ person would have apperared in direct discourse. This 
amounts to picking up the reference of the $1^{\text {st }}$ person pronoun from the actual context of utterance within the domain of a reported context, as indicated by the RS nonmanuals.

RS-mother

IX-1 MOTHER FATHER HOME AGAIN / IX-1
'...that my mother and father would go home again, not me.'

(DSL:Engberg-Pedersen 1995)

There are even more complex cases that involve pronouns which access both the reportive and the actual context: in the LSC sentence (22) the dual $1^{\text {st }}$ person pronoun TWO-OF-US, the $2^{\text {nd }}$ person included in the dual pronoun is ambiguous between the actual addressee of the utterance or the reported addressee. In the former case, we actually have an instance of "mixed" indexicality. However, due to the complexity derived from additional factors in plural pronouns, I leave such cases out of consideration here.

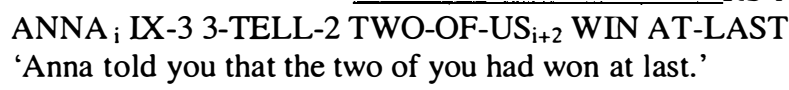

A legitimate question to ask at this point is whether we are actually dealing with the same series of pronouns in RS and non-RS contexts. One could in principle argue that the coarticulation of a manual pronoun with the specific nonmanual markings of RS is actually the realization of a distinct series of pronouns of the logophoric type. This position, though, cannot be sustained mainly for two reasons. First, the nonmanual morphology associated to RS marking is coarticulated with the whole stretch of reported discourse/thought, and not only with the pronominal form. Second, some indexicals other than pronouns can show the same shifty behaviour and that would mean that we systematically have two series of indexicals, one for those referring directly to the main utterance context and another one for those referring to the parameters of the shifted context. Actually, such an assumption would create an even bigger problem, since it entails that we should potentially have two parallel series of lexical items for the whole lexicon (one with RS nonmanual marking and another one without it). For these reasons, I reject this possibility. Let's examine now some data making the second objection clearer.

Although the RS marker extends over the whole reported proposition, not all indexicals need to be interpreted in the reported context. Locative indexicals like HERE do not shift obligatorily in the scope of an attitude predicate such as SAY, and the default interpretation is the one that links them to the spatiotemporal parameters of the main context of utterance. Consider the LSC in (6), repeated here as (23) for convenience: while the $1^{\text {st }}$ person pronoun in the reported thought is interpreted as coreferential with the attitude holder JOAN, the locative indexical HERE refers most naturally to the context of utterance 
(Barcelona), and not to the derived context where the locative parameter is explicitly fixed (Madrid).

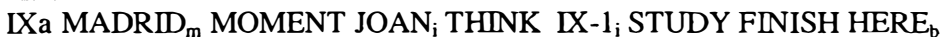
RS-i

'When he was in Madrid, Joan thought he would finish his study in Barcelona.'

However, if the indexical HERE is further specified, as in the minimally modified sentence (24) (=(1)), it can end up referring to the other location, Madrid.

\section{IXa MADRID JOAN ${ }_{i}$ THINK IX-1 ${ }_{i}$ STUDY FINISH HERE MADRID}

'When he has in Madrid, Joan thought he would finish his studies there in Madrid.'

The fact that one and the same indexical (HERE) with associated RS morphology can receive both interpretations argues against the possible alternative mentioned above that would resort to two different series of indexical elements in the lexicon.

Not all temporal and locative indexicals, though, behave in the same way. Some of them, like NOW in (25) or YEAR THIS in (26), do not permit shifted reference to the embedded context. This must be attributed to lexical differences between indexical expressions: in a subset of cases like these, we do find strict indexicality to the main context parameters.

LAST-YEAR JOAN ${ }_{\mathrm{i}}$ THINK IX-1 $\mathrm{i}_{\mathrm{i}}$ STUDY FINISH NOW

'Last year, Joan thought he would finish his studies \{now/\#then\}.'

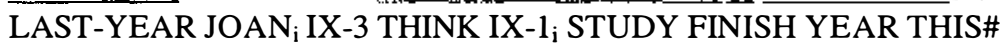

'Last year, Joan thought he would finish his studies $\{$ this year/\#then-that year\}.'

On the basis of Navajo data displaying Direct Discourse Complements, Speas (1999) argues for a split between the system determining deixis for person marking (functional) and the system determining deixis more generally (semantic). In view of the data discussed so far in this paper, we must conclude that such a clear-cut divide does not hold for the SLs at hand, despite the parallelism with some of the Navajo facts. What we have been able to show is that shifted reference of indexicals is not something specific to a particular context parameter.

The proposals made for the set of data with shifting indexicals in certain spoken languages like Amharic could straightforwardly tackle the SL examples of RS such as (1-3) with an introducing reportive/attitude predicate, that is, instances of so-called quotative RS. However, the same analyses are faced with an 
additional problem in instances of non-quotative RS like (7)-(9): no attitude verb is present in the structure in order to license the shifted reading of indexicals, a scenario which is explicitly excluded in Schlenker (2003: 69). In the next section I will sketch an approach that tries to solve the problem without giving up the insights of previous analyses.

\section{Proposal: Point of View Operator}

With the aim to provide a unified account of both introduced and unintroduced instances of RS, I follow the basic insight in Lillo-Martin (1995), where she proposes that a sentence like $(27)(=(9))$ involves a covert Point of View Predicate (POV). The relevant part of the structure is depicted in (28): the covert POV predicate selects an embedded CP and binds the operator in its Spec. In turn, this operator binds the $1^{\text {st }}$ person pronoun in the RS complement.

$$
\begin{aligned}
& \text { MOM }_{\mathrm{i}}{\mathrm{IX}-1_{\mathrm{i}} \text { BUSY }}_{\text {BUS }}^{\text {RU }} \\
& \text { 'Mom's like, I'm busy!' }
\end{aligned}
$$

(ASL: Lillo-Martin 1995)

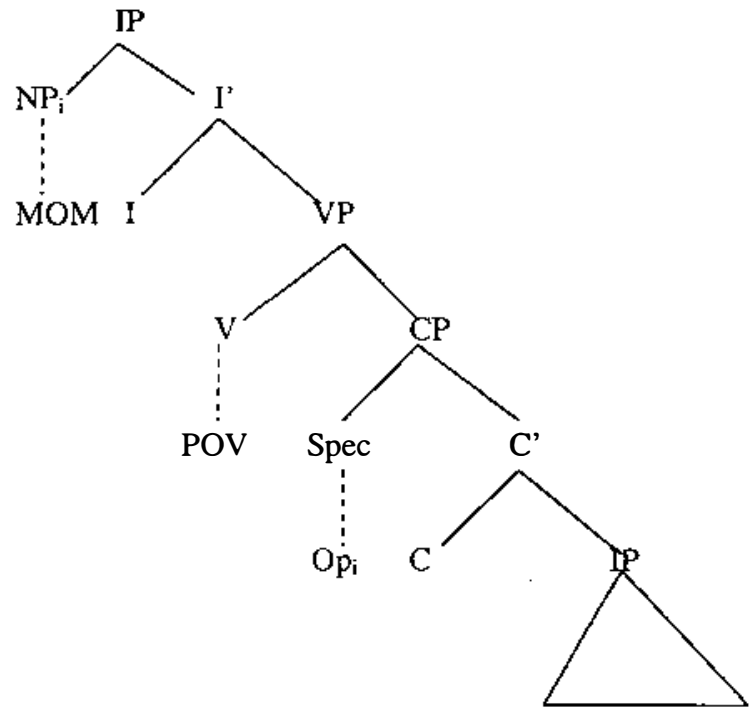

\section{IX- $1_{\mathrm{i}}$ BUSY}

Building on Lillo-Martin's (1995) analysis, I suggest that the type of languages we are looking at instantiate a Point of View Operator (PVOp), rather than a Point of View Predicate. This operator materializes in RS nonmanual morphology and 
accounts for the attested shifted interpretations of indexicals in its scope $\left(1^{\text {st }}\right.$ and $2^{\text {nd }}$ person pronouns, time and locative indexicals). Spreading of nonmanuals over the c-command domain of an Operator has been argued to exist in ASL for other operators such as Wh, Q or Neg (Neidle et al. 2000), whether they are overt or covert: furrowed eyebrows associated with the Wh-Operator in (29) and headshake associated with the Neg Operator in (30).

LOVE JOHN WHO

'Who does John love?'

$$
\begin{aligned}
& \text { JOHN BUY HOUSE } \\
& \text { 'John didn't buy a house.' }
\end{aligned}
$$

(ASL: Neidle et al. 2000)

Unlike Lillo-Martin, though, I argue that PVOp is not a covert reportive/attitude predicate taking a subordinate $\mathrm{CP}$ (the reported proposition), but a covert operator over contexts (à-la-Schlenker) sitting in a very high projection of the functional structure of the clause (cf. Cinque 1999 on the expanded left periphery of the clause, Speas \& Tenny 2003, Speas 2004). Tentatively, I will assume that this projection is Speech Act Phrase, as proposed in Speas $(1999,2004)$ in order to account for a number of related facts. The PVOp would occupy the head of this projection and determine the morphological and interpretive properties of the RS structure within its c-command domain. If such an analysis is on the right track, it is able to unify both the quotational and non-quotational instances of RS, as it does not link context shift to an overt attitude predicate. However, in cases of lexically introduced RS, it remains to be determined how the overt attitude predicate interacts with the empty PVOp, as both seem to fulfill the same function in the analysis. For a minimal variant of example (27) with lexically introduced $\mathrm{RS}$, we would have to posit a structure like the one under (31). The extra assumption required would be that the two attitude operators compose semantically as a result of the incorporation of PVOp into the lexical verb (a comparable movement of the head Speech Act into the selecting predicate has been put forth in Speas 1999). At this point, though, the details and consequences of such a proposal remain to be worked out. 
(31)

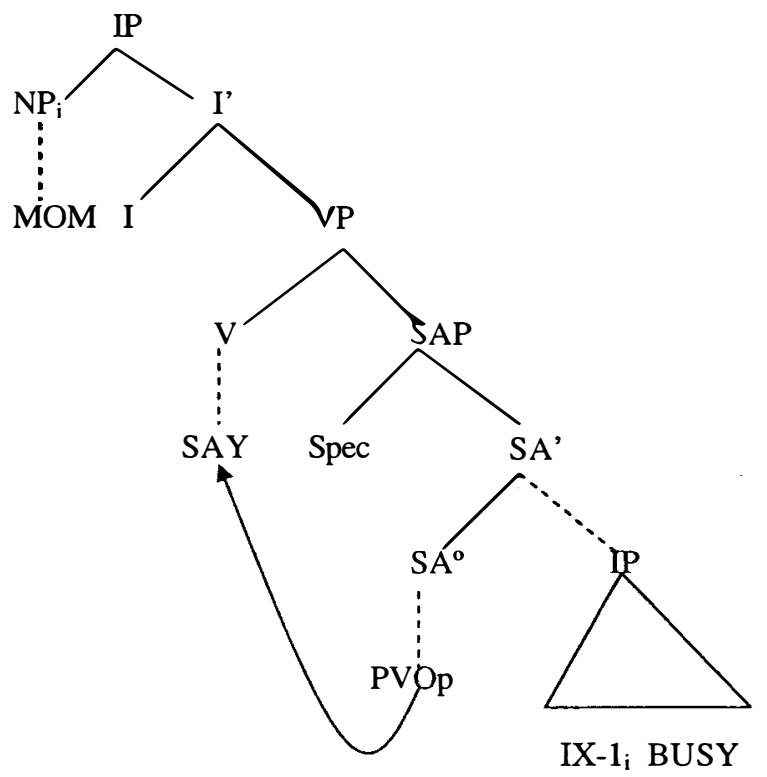

In contrast to other analyses, the one sketched here does not reduce the issue of RS to the interpretation of $1^{\text {st }}$ person pronoun (Zucchi 2004), since other contextual variables display a comparable pattern of behaviour. It offers strong confirmation for the idea that context variables (author and addressee, time, location) in a derived context can be bound independently from each other by an attitude operator or identified with the value of the parameters in the main context of utterance.

\section{Some Consequences}

\subsection{Independent Shift of Indexicals}

On the basis of the SL data discussed here, one is forced to relativize the crosslinguistic validity of the "Shift-Together Constraint" (see (32)) proposed in Anand \& Nevins (2004) for Slave and Zazaki.

\section{Shift-Together Constraint}

Shiftable indexicals must shift together.

(Anand \& Nevins 2004)

As we have seen, when indexical pronouns ( $1^{\text {st }}$ and $2^{\text {nd }}$ person) shift under $R S$, locative and temporal indexicals can still refer to the actual context of utterance, 
which appears to instantiate direct deixis in their unmarked interpretation. In addition, under appropriate circumstances some of them can shift, too, with some exceptions that must be derived from their lexical specification. However, it is not clear either that all pronouns in a sentence must shift together, as we find examples of shifted $1^{\text {st }}$ person next to a non-shifted $2^{\text {nd }}$ person in a reported context (see (22) above). Such cases deserve further investigation before they can be consistently incorporated into the general picture.

\subsection{Quantifier Binding of Shifted Pronouns}

Furthermore, additional support can be offered for Schlenker's (2003) binding analysis of contextual variables with fresh evidence from SL showing quantifier bound readings of a shifted first person prononun within the scope of RS. The LSC instances of this are the following ones:

RS-i

(33) PUPIL ALL ${ }_{i}$ THINK^SEE.refl IX-1 ${ }_{i}$ INTELLIGENT SUPERLATIVE 'Every pupil thinks that he is the most intelligent.' RS-i

eg: 1 eg:front PUPIL EACH $_{\mathrm{i}}$ THINK^SEE.refl IX $^{\wedge} 1_{\mathrm{i}}$ INTELLIGENT SUPERLATIVE 'Each pupil thinks that he is the most intelligent.'

A comparable case was independently observed for Abe by Koopman and Sportiche (1989): in (35) a $3^{\text {rd }}$ person referential pronoun (akin to the behaviour of $1^{\text {st }}$ and $2^{\text {nd }}$ person pronouns) can be bound by the main quantificational NP subject. Their hypothesis is that this is made possible by the occurrence of the complementizer $k O$. Similarly, for the SL cases in (33)-(34) I would like to tentatively suggest that it is the covert PVOp what mediates in the bound reading of the embedded subject pronoun.

$$
\begin{array}{llllll}
\text { apoOUN } & \text { ye } & \mathrm{hE} & \mathrm{kO} \quad \mathrm{n}_{\mathrm{i}} & \text { ye } & \mathrm{SE} \\
\text { nobody } & \mathrm{Neg} & \text { said } & \mathrm{Comp} \text { he } & \text { is } & \text { handsome }
\end{array}
$$

(Koopman \& Sportiche 1989: 584)

Note in passing that the SL examples discussed in this subsection constitute strong support for the idea that pronominal indices are actual pronouns, and not just pointing/mostly gestural expressions, as has been often defended in the literature, most prominently by Liddell (see for instance Liddell 2000 for an overview of this position; in favour of the linguistic status of pronouns, with an argument from RS, see Meier 1990). ${ }^{7}$ 


\subsection{Is PVOp A “Monster"?}

As a consequence of the overall discussion of SL data in this paper, one can defend that Kaplanian indexical "monsters" do exist in SLs. The PVOp we find in SLs instantiate such a monster, as shiftable indexicals in its scope are not "directly referential" to the main context of utterance. Zucchi (2004) offers a unified analysis of the quotational and non-quotational RS in terms of the presupposition associated with the $1^{\text {st }}$ person morphology in RS, namely that the $1^{\text {st }}$ person is coindexed with another term in the discourse other than the utterer. However, this might be a simplification, because we have already seen that the referential shift in these constructions can also affect $2^{\text {nd }}$ person pronouns/agreement, locative and time indexicals, and sometimes independently of each other when they cooccur. A further piece of evidence of context-dependent elements that shift are affective elements such as FED-UP in (36): they get interpreted with respect to the shifted $1^{\text {st }}$ person, and not with respect to the actual utterer.

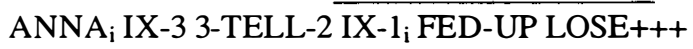

RS-i

'Anna told you that she is fed up with losing all the time.'

\section{Concluding Remarks}

Indexical shift seems to be pervasive within what is known as RS, which is present in most if not all SLs described to a bigger o smaller degree. It has been mostly attested for pronominal reference shift (and corresponding verb agreement), but there is little discussion in the literature about other indexicals like temporal and locative deictic expressions. The phenomenon of indexical shift in reportive/attitude contexts described in less familiar spoken languages seems to be extremely robust in SLs.

The main points of the discussion can be summarized as follows:

(i) RS in SL has properties of both direct and indirect reported discourse, as in several spoken languages.

(ii) The interpretive and morphological properties of RS can be derived from a Point of View Operator.

(iii) Quotational and non-quotational instances of RS can be accounted for in a unified fashion, as in Zucchi (2004).

(iv) Indexicals in $\mathrm{RS}\left(1^{\text {st }} 2^{\text {nd }}\right.$ person pronouns, locative and time indexicals) can all shift under appropriate conditions.

This work constitutes just a first attempt at addressing in SL the same kinds of questions raised in the semantics literature on indexical reference in 
reportive contexts. As we have seen, despite the effects of the visual-gestural modality, some of the the "uncommon" facts described for certain spoken languages are replicated in SLs. This allows us to evaluate the empirical crosslinguistic validity of concrete aspects of recent proposals on indexical shifting.

One question, though, that I have only hinted at in section 6.2 is the $a$ priori possible modality effect in shifting reference in reportive contexts. As mentioned there, it has been claimed that SLs do not have actual pronouns and that what we have been calling pronouns here must be reduced, at least in part, to pointing or indicating gestures. Some of the phenomena discussed here obviously argue against such a position. Still, there remain quite important issues to be addressed in this domain, such as the relation between actual deixis and grammaticalized deixis in SLs, but these are questions that must await future work.

\section{Endnotes}

*I would like to thank the audiences at SALT 15 (Los Angeles, April 2005) and at the Sign Language Workshop Signa Volant (Milan, June 2005) for their valuable comments and criticism. Special thanks go to Rajesh Bhatt, Ivano Caponigro, Carlo Cecchetto, Gennaro Chierchia, Carlo Geraci, Teresa Guasti, Ed Keenan, Victor Manfredi, Steve Parkhurst, Roland Pfau, Bernhard Schwarz, Yael Sharvit, Markus Steinbach and Sandro Zucchi. This version of the paper reproduces the oral presentations at those events quite faithfully. The input received on those occasions will be incorporated in a revised version. This work would have been impossible without the collaboration of my Deaf colleague Santiago Frigola, and the comments of other LSC informants such as Josep M. Boronat, Mireia Solé and Pedro Frigola. The research was partly made possible by a grant awarded by the Spanish Ministry of Education and Science to Josep Quer (BFF2003-04867).

'If not indicated otherwise, the examples appearing in this paper are from LSC.

${ }^{2}$ I follow the usual glossing conventions in the SL literature, according to which manual signs are represented by the capitalized word corresponding to the translation of the sign. The scope of nonmanual markings is represented with a line that spreads over the manual material with which it is coarticulated. The relevant abbreviations for the purposes of this paper are the following ones: \#VERB-\# (verb agreeing with subject and object; the number before the verb refers to the grammatical person of the former and the one after the verb refers to the latter); AGR (unbound agreement marker); eg (eyegaze); IXa (locative index poiting to locus $a$ ); IX-\# (pronominal index; the number corresponds to person); hs (negative headshake); RS (role shift); t (topic marking); wh (wh marking); +++ (repetition of the sign). The referential indices $i, j$, etc. link the first person role in $\mathrm{RS}$ fragments to the intended author of the reported utterance.

${ }^{3}$ Pronominal reference in the singular is typically realized in SLs as an index (glossed as IX) consisting in a pointing handshape that is oriented towards present referents (IX-1=author, IX-2=addressee, IX-3=[-author, -addressee $]$ present 
referent). Non-present referents are localized in a locus of the signing space to which IX points.

${ }^{4}$ The first translation is the one offered originally by Lee et al. (1997), but in order to remain neutral as to the direct/indirect character of RS, the indirect report version in English has been added.

${ }^{5}$ In the oral presentation of this work at SALT 15, some colleagues in the audience rejected Schlenker's characterization of these facts with "two days ago". Pending further examination, I keep it in the written version for the sake of Schlenker's argument.

${ }^{6}$ Most of the SLs documented to date group their verbal lexical items in three main categories according to their behaviour with respect to agreement: (i) plain verbs, which do not agree; (ii) agreeing verbs, which display agreement with subject and/or object, and (iii) spatial verbs, which agree with their locative arguments (see Padden 1988). Some languages have additional means to show agreement with plain verbs, like agreement auxiliary predicates. The AGR sign in (19) is such a case in LSC.

${ }^{7}$ This argument becomes more forceful if pronouns turn out to be bound by a negative quantifier in the main clause or by a second person plural subject. The LSC data elicited so far seem to confirm this prediction. Thanks to Gennaro Chierchia for making this point.

\section{References}

Anand, Pranav and Andrew Nevins: 2004, 'Shifty Operators in Changing Contexts', in Proceedings of SALT 14.

Bhat, D.N.S.: 2004, Pronouns, Oxford University Press, Oxford.

Cinque, Guglielmo: 1999, Adverbs and Functional Heads. A Cross-linguistic Perspective, Oxford University Press, Oxford.

Engberg-Pedersen, Elisabeth: 1995, 'Point of View Expressed Through Shifters', in K. Emmorey \& J.S. Reilly (eds.) Language, Gesture, and Space, 133154., Lawrence Erlbaum Associates, Hillsdalle, NJ.

Frajzyngier, Zygmunt: 1993, A Grammar of Mupun, Dietrich Reimer Verlag, Berlin.

Kaplan, David: 1989, 'Demonstratives', in J. Almog et al. (eds.) Themes from Kaplan, 481-563, Oxford University Press, New York.

Koopman, Hilda and Dominique Sportiche: 1989, 'Pronouns, Logical Variables, and Logophoricity in Abe', Linguistic Inquiry 20, 555-588.

Lee, Robert G. et al.: 1997, 'Role Shift in ASL: A Syntactic Look at Direct Speech', Report \#4, ASLLRP, Boston University.

Liddell, Scott K.: 2000, 'Indicating Verbs and Pronouns: Pointing Away from Agreement', in K. Emmorey \& H. Lane (eds.) The Signs of Language Revisited, 303-320, Lawrence Erlbaum Associates, Mahwah, NJ.

Lillo-Martin, Diane: 1995, 'The Point of View Predicate in American Sign Language', in K. Emmorey \& J.S. Reilly (eds.) Language, Gesture \& Space, 155-170, Lawrence Erlbaum Associates, Hillsdalle, NJ. 
Meier, Richard P.: 1990, 'Person Deixis in American Sign Language', in S.D. Fischer \& P. Siple (eds.) Theoretical Issues in Sign Language Research, Vol. 1: Linguistics, 175-190, University of Chicago Press, Chicago.

Metzger, Melanie: 1995, 'Constructed Dialogue and Constructed Action in American Sign Language', in C. Lucas (ed.) Sociolinguistics in Deaf Communities, 255-271, Gallaudet University Press, Washington, D.C..

Neidle, Carol et al.: 2000, The Syntax of American Sign Language. Functional Categories and Hierarchical Structure, The MIT Press, Cambridge, MA.

Padden, Carol A.: 1988, Interaction of Morphology and Syntax in American Sign Language, Garland Publishing, New York/London.

Poulin, Christine: 1994, 'Null Arguments and Referential Shift in American Sign Language', MIT Working Papers in Linguistics 23, 267-281.

Poulin, Christine and Christopher Miller: 1995, 'On Narrative Discourse and Point of View in Quebec Sign Language' in K. Emmorey \& J.S. Reilly (eds.) Language, Gesture \& Space, 117-131, Lawrence Erlbaum Associates, Hillsdalle, NJ.

Schlenker, Philippe: 2003, 'A Plea for Monsters', Linguistics \& Philosophy 26, 29-120.

Speas, Margaret: 2000, 'Person and Point of view in Navajo Direct Discourse Complements', in E. Jelinek (ed.) WCCFL in Honor of Ken Hale, The MIT Press, Cambridge, MA.

Speas, Margaret: 2004, 'Evidentiality, Logophoricity and The Syntactic Representation of Pragmatic Features', Lingua 114, 255-276.

Speas, Margaret and Carol Tenny: 2003, 'Configurational Properties of Point of View Roles', in A.M. di Sciullo (ed.) Asymmetry in Grammar, John Benjamins, Amsterdam.

Zucchi, Alessandro: 2004, 'Monsters in The Visual Mode?' Ms Università degli Studi di Milano. 